\title{
Drugs of Choice, Drugs of Change: Egyptian Consumption Habits since the
} 1920 s

Philip Robins, Middle East Centre, St Antony's College, University of Oxford, UK

\begin{abstract}
Much has been written and published about the 25 January 2011 Egyptian revolution from the perspective of contemporary history and political science. Much less attention has focused on social policy. I am unaware of any scholarly material that has dealt with illicit drugs during the critical 2011-2016 period, yet increasing drugs consumption provided a social backdrop to the events of that period. This paper identifies historical trends in illicit drugs consumption over the course of the last century to the beginning of the 'Arab Spring'. During much of this period hashish was the 'drug of choice'. The paper argues that drug consumption was on the rise in Egypt well before the downfall of President Husni Mubarak in February 2011, but that it has grown markedly since the ousting of the former president. It will ask which have been and are the drugs of choice in contemporary Egypt. It will further ask how this composition has changed and why, giving special focus to the relatively new mass, opioid drug, Tramadol.
\end{abstract}

Key Words: Egypt; Illicit drugs; Tramadol; 'Arab Spring'. 


\section{Introduction}

Drugs have regularly featured in the social profile of consumption and leisure in modern Egypt, at least when consumers have been able to afford them. At certain times, such as in the 1920s and 1930s, the era of Egypt's 'white drugs' epidemic, the profile of the drugs in question have included heroin and even cocaine ${ }^{1}$. Until the approach of the millennium, however, there was arguably something close to a consensus that Egypt's drug of choice was hashish. As one fictional drugs commentator put it recently hashish is not a drug, 'it's chocolate, the elixir of life'2.

Just because this has been the profile of drug use in the past - the white drugs era had effectively passed some eight decades ago - does not mean that such a situation will simply reproduce itself indefinitely. The marijuana-style drug called bango has emerged as a significant drug of choice over the last two decades, especially. This trend has also surfaced, notably in the Sinai Peninsula and the east of the country, where the authority of the state is often contested. There is strong and recurrent anecdotal evidence that bango has been grown and trafficked in the eastern governorates of Egypt. For example, Al Masry al Youm, one of Egypt's leading newspapers, published in January 2012 a short article reporting that four tons of bango had been caught being smuggled from the Sinai in a truck. ${ }^{3}$ For a second example, a four line report in the same paper a month later refers to half a ton of bango being apprehended east of Ismailiyya, the drugs being caught in a car on the way to Sinai. ${ }^{4}$ Egypt also developed something of a fondness for synthetic drugs, notably in the 1980 s and the 1990s. It was against this background of a discernible rise in drug-taking across society that a relatively little known substance emerged rapidly to transform the market. This was a manufactured opioid, marketed under the commercial name of Tramadol. An analgesic, this has become nothing less than the 'epidemic drug' of the anti-Mubarak, revolutionary period.

This paper is concerned to explore the pattern and composition of drug taking in Egypt, before, during and immediately after the period of revolutionary turmoil under President Mubarak, here defined as spanning the period between the run-up to the 25 January 2011 revolution and the restoration of a military dominated regime with the election to the presidency of Abdul Fatah al-Sisi in May 2014. In doing so, it will contextualise Egypt's experiences by introducing drug-taking in historical perspective. It will make judgements about trends in the consumption of drugs, as well as when certain drugs were on the rise and others were on the wane, and explain why. The second part of the paper will focus on the transformatory impact of Tramadol. Drawing on the work of Egyptian anti-drugs epidemiologist, Professor Emad Hamdi of Cairo University, it will seek to explain the origins, impact and possible consequences of Tramadol. ${ }^{5}$ This paper primarily uses a qualitative as opposed to a quantitative method, though it does make use of quantitative data available, primarily through the work of Professor Hamdi and his Cairobased medical research team. The material for this paper was assembled during three research trips to Egypt during the revolutionary period of 2011-2012, with a fourth research 
visit taking place in July 2016. A total of 31 or more in-depth interviews were conducted with health service and policy professionals, and law enforcement personnel. In addition to these interviews, two focus groups of approximately two hours duration for each were also convened in order to test the indicative nature of the material.

\section{Illicit Drugs Consumption in Modern Egypt}

Much of Egypt's engagement with illegal drugs has comprised an uneasy, fluctuating relationship between informal markets and formal state bodies. This has taken place against the strong yet unclear legacy of monarchical times. More latterly, there has been the spectre of a looming international control regime becoming fitfully more salient from the earliest part of the twentieth century. In many ways, the binary tensions involving the two domains continue today.

Cairo first began to address the drugs issue in 1879, with its attempt to control the public circulation of drugs. The cultivation of hashish in Egypt was the subject of a special law of March 1884. This was followed by the adoption of a law to proscribe the sale of hashish in the coffee houses of Cairo in 1895. The only existing law in Egypt which touched the question of drug trafficking was contained within the decree of 15 September 1904, which is actually most concerned with the regulation of pharmacies. No special mention is made in that law about certain types of drugs, such as cocaine, morphine and opium.

The litany above suggests that the legal infrastructure for dealing with drugs-related issues in Egypt was ragged and inconsistent to say the least. For example, the cultivation of opium poppy was prohibited in October 1918, but permitted again in $1920 .{ }^{6}$ Otherwise, what Pino Arlacchi, former Director-General of a specialist UN agency on drugs and crime, has called an 'open availability model' typified the international drugs market Egypt included, that is to say a period of largely ineffectual control. ${ }^{7}$

Pressures on Egypt to intensify its engagement with the emerging multilateral drug regulatory regime received a twin boost in the 1920s. The post First World War period witnessed the influx of white drugs into Egypt at largely affordable prices. At the same time, Cairo, as with other emerging administrations in the developing world, was obliged to respond to the increasingly intrusive multilateral framework of drugs control contained within the League of Nations. So, for example, Egypt's new anti-narcotics decrees made both trafficking and the possession of drugs a criminal offence. ${ }^{8}$

Egypt's first anti-narcotics law was published in December 1927; it established a state body for the elimination of illicit drugs. Since then, Egypt has continued upon a spasmodic journey in the direction of the institutionalisation of anti-drugs activities. Egypt's current specialist anti-drugs police, the Anti-Narcotics General Administration (ANGA), was set up in 1976 according to Deputy Director-General, Tareq Ismael. ${ }^{9}$ It now possesses an extensive framework comprising 11 separate departments. ${ }^{10}$

According to this drugs regime-in-the-making, there was no multilateral framework by which the early application of a nascent international law could be applied, even at a 
purely symbolic level. ${ }^{11}$ By contrast, countries could both market and sell their drugs externally, and regulate the sale and distribution of their drugs locally. The popularity of drugs as a consumer good and as a health product ideally suited for self-medication meant that they could become a significant export market.

Over time, there were mixed feelings at the existence and operation of the open availability model. The US increasingly wanted to regulate global conduct in relation to drugs. By contrast, much of the rest of the world, especially those states involved in the cultivation of significant volumes of drugs, were content with the preceding arrangements. It was the US, as the world's emerging superpower, with a penchant for a formal legalism in international as well as its national affairs, which won the day.

The old model was superceded by the so-called 'penal control model', which, as the name suggests, was an approach more markedly interventionist and punitive than before. This philosophy would soon result in a process of institution building, in order to prompt and then expand this type of restrictive norm diffusion. Though nominally multilateral in approach, in reality the building of an international regime was largely left to the handful of global powers of the day, and their bureaucratic specialists, led by the US. By 1931 a raft of multilateralism had resulted. ${ }^{12}$ Little of it had been driven by or was especially pertinent to contemporary Egypt.

\section{Egypt and its Drugs of Choice ${ }^{13}$}

\section{Incremental Criminalisation}

As the penal control model gained greater traction in the field of multilateral interaction in general, and relations between Egypt and the US in particular, one might have expected greater bilateral tensions to begin to stoke up. This was largely not to be the case, however, at least not initially. The Egyptian side managed the potential policy dissonance between them over such matters by keeping a discrete distance. The widespread and unregulated buying and selling of drugs was discontinued. Instead, there was a tacit understanding that such trade should be largely confined to one main part of Cairo, the poorer neighbourhood of El-Batniyyah, ${ }^{14}$ which had enjoyed an independent character since the city of Cairo was in its infancy. The material on El-Batniyyah is derived from participant observation, together with selected interviews with: a shopkeeper, whose father had run a bookshop in the drugs heyday; a group of manual workers shovelling sand at the entrance to a club; a man introduced as 'the man who really knows', whose parents had sold drugs in the area, but who had been imprisoned in the wake of the 1980 and subsequent a taxi driver plying the streets to and from the district; a member of the upper middle class, who used to buy hashish in the district.

Curiously, the area was located in a compact neighbourhood, just up the hill from the historic Islamic centre of Al-Azhar University. There were two entry points. The drugs, 
which included hashish, heroin and others, were sold on trestle tables, largely in the open. Most of the time the authorities left the drugs trade well alone. Occasionally, the area was visited by the police, often for purposes of their own consumption. Even when law enforcement bodies arrived with a less benign agenda little appeared actually to change, or at least no more than temporarily. Sometimes, the drugs sellers were dispersed in a token attempt to clear up an area of open criminality. This tended to be perfunctory at best. Typically, such drug peddlers would escape with their merchandise on mopeds, allowing them to navigate the narrow, winding streets with greater success than their pursuers. They would soon return to take up their activities as before. Alternatively, dealers would not even bother with such a charade. Those who felt a particular entitlement simply stood their ground and attempted to intimidate the police officers and other law enforcement members in their midst.

Eventually, however, the situation became unsustainable. US President Richard Nixon's 'War on Drugs' raised the issue to a much higher bilateral priority for the US than had hitherto been the case. Saving American citizens from drugs cultivated abroad, and especially in the Middle East, became a central plank of American foreign policy in the 1970s and 1980s. With that in mind, the administration of President Jimmy Carter raised the issue more robustly with the Egyptian government. Initially, the Egyptian response was limited. After all, wasn't President Anwar Sadat, Egypt's great peace-maker, supposed to have smoked hash, and even chewed opium while delivering speeches? Moreover, Anwar Sadat's brother, Ismat, was head of the port of Alexandria, and hence able to control much of the trafficking of Egyptian contraband, drugs included. ${ }^{15}$

Eventually, the Americans prevailed, at least at an official level. From the early- to mid-1980s, access to El-Batniyyah was effectively closed to routine drug trading, according to one Egyptian famer who used to buy hashish in the area. ${ }^{16} \mathrm{~A}$ dirty wasteland was temporarily left behind. The land covered roughly a mile square. The Agha Khan Foundation, a wealthy INGO based in the Islamic World, would help the cause of the Egyptian state by bearing some of the economic cost of subsequently redeveloping the area. In reality, the choking off of hashish production simply inflated demand for bango. ElBatniyyah's edgy aura continued for a brief period of time, for example, through the making and transmission of a feature film and a television drama series about the neighbourhood. The film in particular was claimed to be an accurate portrayal of a neighbourhood drugs economy in practice. However, that only proved to be a temporary respite for the drugs district of El-Batniyyah. Now, some two decades later, all that remains is narco-nostalgia.

\section{Pre-revolutionary Drugs Landscape: Bango}

Bango has strong roots in Egyptian society and its neighbouring countries, such as Sudan. It has increasingly become the drug of choice or something comparable in Egypt for a mixed social grouping of intellectuals, students and members of the working class. It is primarily sold within the 50-100 gram weight range, but with marked fluctuations within these weight 
ranges reported. Bango is often cultivated by bedouin tribes, for their own use and for exporting, especially in the east of Egypt. Bango has been placed in Category A (alif) in terms of the seriousness of illegal drug consumption, the same level as hashish. One of the great advantages of bango is the difficulty of adulterating the drug compared to cocaine, heroin and even hashish. The daily cost of consumption is around fE30-50 for both bango and hashish.

Part of the bango harvest is transported to the Gaza Strip, together with other high return contraband goods like small arms and drugs, such as heroin. Prior to the summer 2014 Gaza war between Israel and the Palestinians, bango was trafficked to Israel via the extensive tunnel network, constructed informally by Palestinian criminals-cumentrepreneurs. The Egyptian authorities tried to eradicate these tunnels through the use of water bombs. When this failed, they returned to the use of conventional ordinance. ${ }^{17}$ It is unclear to what extent Israeli efforts to destroy the tunnels after July 2013 have succeeded in ending this double contraband of drugs and arms.

\section{Hashish}

There is a debate in Egypt about the dangers associated with hashish. There are broadly three positions held. Some maintain that hashish should not be viewed as an addictive drug, but one that has been part of the socio-cultural fabric of the country for as long as anyone can remember. As such, hashish should not be regarded as 'a drug' at all, but as a culturally embedded substance and key part of an associated sub-culture, comparable to the warm beer of legend, consumed in England with an eye to the country's 'glorious' past. In regional terms, this would make hashish analogous to the regular consumption of qat in countries such as Yemen, even more so now that the cloak of illegality has now been extended to this narcotic. This view would be adamant in not seeing hashish as an addictive substance, and hence not as a 'gateway' drug, leading to the possible consumption of other, more dangerous substances. Those who fret about the risks of the consumption of hashish would tend to be dismissed by this tendency as being excessively 'bourgeois' according to Ahmed Fawzi, Secretary-General of the Social Democratic Party. ${ }^{18}$

A second view would be to see hashish, if not as addictive, then certainly as habit forming, a view held by Dr Azmi, Dr Munir, Health spokesman for Free Egyptians Party, Salam Hospital, Muhandissin, Cairo. ${ }^{19}$ It may be admitted that the 'odd smoke' might not do the consumer any harm. However, if hashish consumption really is a component of Egyptian national culture, as some of its proponents zestfully believe, then a life time's worth of consumption may well result in the exaggeration of some undesirable health and social traits prevalent in Egypt, such as lethargy and incoherence. This point of view underlines the ambiguity of the 'hash as culture camp'.

A third category of analysis would be to see hashish as altogether more pernicious. Hashish consumption would risk much more than a simple dalliance with a soft drug. It 
could result in a progression to 'drug addiction'. This would be the traditional 'hash as gateway' approach, which would be wary of the drug from the outset.

\section{Heroin}

As with cocaine, Egypt had a major problem of addiction and of lethargy with heroin consumption in the 1920s and 1930s. While Egypt largely divested itself of the former, the latter proved more difficult to dislodge. By 2012, it was possible for the specialist NGO community to conclude that 'heroin is really big in Egypt'. ${ }^{20}$ In the case of heroin, consumption in Egypt had rocketed not merely during the period of the revolution, but commencing beforehand. For instance, Essam Youssef's infamous reality novel entitled $A 1 / 4$ Gram was first published in 2008 (English edition 2009), ${ }^{21}$ crucially impacting Egypt before the first stirrings of the protests that would bring down Husni Mubarak. The book told the story of a group of upper middle class Egyptian university students, who go on an orgy of heroin-fuelled drug taking in order to alleviate their lives of boredom and worthlessness.

The heroin is alleged by the UN to come from Turkey according to Faisal Higazi of the UNODC in Cairo, ${ }^{22}$ and before that Afghanistan. The Ministry of Health in Egypt has argued against the establishment of a methadone programme to help alleviate the impact of the drug. The primary argument against such a policy is that Egypt does not have the pharmaceutical system capable of administering such a programme and it will therefore run the risk of leaking onto the open market, with even larger numbers becoming drug dependent. This was the concern raised by Dr Nasser Loza of Behman Hospital, in Hilwan. ${ }^{23}$

Table One: Prices of Illegal Drugs in Egypt, 1995-2012.

\begin{tabular}{|lllll|}
\hline Drug Type: & Bango & Cocaine & Hashish & Heroin \\
\hline Year & & & & \\
\hline 1995 & N/A & N/A & N/A & \$100/gram \\
\hline 2010 & N/A & N/A & N/A & $\$ 12.5-35 /$ gram \\
\hline 2011 & $\$ 2.8 /$ gram & \$160/gram & N/A & $\$ 25 /$ gram \\
\hline 2012 & \$2.2/gram & N/A & \$15/gram & \$21/gram \\
\hline
\end{tabular}

Sources: Compiled by the author from separate sources, including Faisal Hegarzi, UNDOC, ${ }^{24}$ and Medhat Maher Kamel, Shubra Drop-In Centre 25

\section{Changes in Patterns of Drug Consumption}

There can be little doubt that drug consumption rose significantly during the period of the anti-Mubarak ouster and its immediate aftermath. This is certainly the overall conclusion of the managing-director of the addiction unit at the Ministry of Health, Dr Tamer alAmroushy. This was established by extensive, evidence-led research, which covered not only Cairo, but some of the country's other governorates as well. Led by Prof Emed Hamdi, renowned Egyptian psychiatric physician, and funded by the Ministry of Health, 98,000 
Egyptians were interviewed about their substance consumption habits over a five year period. Of this figure, some 39,000 people polled were resident in Cairo. The sample was as widely drawn as was feasible, with people of various ages, backgrounds and neighbourhoods being included, and with the survey conducted over two separate periods of time. Interviews were conducted with Cairenes in designated places, such as schools and clinics. If anything, the nature of the sample may have encouraged a higher level of conservatism in its responses, as people presumably would have displayed a reluctance to be interviewed, especially in close proximity to their peers.

Nevertheless, the polling turned up several unexpected conclusions. The main headline finding was that the prevalence of substance consumption in Cairo (that is including alcohol, but not tobacco) has achieved record levels, and hence was much higher than expected. In Egypt, the consumption of alcohol is not highly significant relative to other forms. In fact in many governorates alcohol such as beer is not served, even though hashish may be. In short-hand cultural terms it is often said that in the Middle East alcohol is known as the drug of the infidel, while hashish is known as the drug of the Muslims!

In total, between $5 \%$ and $7 \%$ of drug-takers were judged to be regular 'abusers' to the point of showing signs of having an addiction. This equates to between $1 \mathrm{mn}$ and 1.4 $\mathrm{mn}$ members of the population. Prof Hamdi made it very clear that this figure did not apply to casual drugs use. When casual use is factored in, the rate rises sharply to $25 \%-30 \%$ of the total. That is to say that almost one-third of the adult population of Cairo is a regular consumer of drugs. Of this figure for casual use, $90 \%$ were identified as consumers of hashish, $35 \%$ alcohol, $32 \%$ opiates, $27 \%$ the abuse of pharmaceutical drugs, $25 \%$ solvent and related abuse, while $3 \%$ used cocaine and other types of amphetamines.

The size and extensive nature of the survey has also enabled us to shade in some of the gaps relating to the abuse of illicit drugs in Cairo and elsewhere. For instance, the report found strong correlations between drug use, education and employment. Those with only a primary school education or less were more likely to become drug 'abusers'. The unemployed and those on modest earnings or with low status jobs were disproportionately likely to be represented among regular users. Moushira Khattab, head of the National Council for Childhood and Motherhood and close advisor to Suzanne Mubarak, the former president's wife, claimed in 2012 that drug dependency for Egyptian women was growing at an alarming rate, especially in the area of non-prescribed 'prescription' drugs, such as cough medicines. ${ }^{26}$ The survey also showed that males were three times as likely to use these substances as females, though based on other research the figure for females may have been exaggerated, for instance Sleem estimates that $5 \%$ of drugs users are female in Lebanon, a country where one might have expected a larger proportion than in Egypt. ${ }^{27}$ The youngest recorded age of drug consumption dropped to 10 years old, from 12 years old before. Drug use among bedouin was significantly higher. Religious background suggested that Christians were more likely to be casual users, while Muslim users were more likely to be problem users. Prof Hamdi ended this part of his survey by observing: 'Under the old regime, the relationship between work and success, and morals and values were stripped 
away, obviously leading the vulnerable - the young, poor and uneducated - to fall deep into addiction'28.

\section{Emergence of Tramadol}

Intriguing as the overall findings of the study were, the biggest surprise for Hamdi and NGOs like Freedom, was the sudden emergence of a synthetic, opioid drug, the use of which had sky-rocketed during this time. Tramadol was nothing less than the big expansion drug of the post-revolutionary period. Drawing on his research data, Hamdi claimed that there was nothing less than 'an epidemic' of Tramadol taking place, especially among the young. Tramadol was 'spreading like wildfire', especially within the category of urban drug users, among whom it was claimed to be 'as common as cannabis'.$^{29}$ The age-impact sensitivity connection between Tramadol and other psychotropic substances more generally seems in part explained by their only having come onto the Egyptian drugs scene over the preceding five or six years, according to Mustafa Bader, Deputy Director-General, Anti-Narcotics General Adminitration (ANGA) in Egypt, ${ }^{30}$ and Mohamed Yahya, of the Amr Khalid organisation $^{31}$.

Tramadol is a synthetic drug, an opioid painkiller. Chemically and pharmaceutically, Tramadol and heroin are the same thing. Tramadol increases the brain's serotonin levels. It also possesses some anti-depressant properties. This explains why Tramadol as an opioid, makes the user feel highly energised. It strongly suggests that regular takers of Tramadol build up a resistance to the drug, this tolerance obliging a greater level of consumption in order to achieve the initial effects. The negative physical effects of Tramadol include depression, fatigue and stomach ailments. Other characteristics of chronic use include a reduction in empathy and, in extremis, epileptic fits. The treatment of Tramadol's sideeffects was regarded as being difficult, attested one practicing professional, Abdul Rahman Al-Rashidy, Psychiatric Counsellor at the Maadi Rehabilitation Centre. ${ }^{32}$ Meanwhile, there was also a claim that there had been an upsurge in domestic violence as a result of the use of the drug. Attacks on women had increased generally, owing to an apparent recklessness prompted by such consumption.

\section{Origins}

Tramadol was first introduced in Egypt as a medication for cancers and bone diseases. It was manufactured in Germany and then locally, in some of Egypt's pharmaceutical factories. The substance is best known within drugs circles in Egypt based on weight, the $220 \mathrm{mg}$ and $225 \mathrm{mg}$ tablets also being known as 'the strawberry' and 'the apple' respectively. ${ }^{33}$ Previously, Tramadol circulating in Egypt had invariably been manufactured in the country. From the anti-Mubarak revolution onwards, the control of drugs became much harder. Egyptian Tramadol no longer found itself operating in a closed market. 
Increasingly, Egyptian Tramadol faced a globalisation of supply including competition with Tramadol made in China and India, ${ }^{34}$ with the quality of production of a dubious standard. The psychotropic drugs were often routed through Jabal Ali Port in Dubai, one of the world's largest container ports, and a haven for illicit trade. According to Mustafa Bader of ANGA, it is then delivered to Egypt through its main seaports, notably Alexandria. ${ }^{35}$ For example, in 2010, Tareq Ismael of ANGA claimed the agency had seized $132 \mathrm{mn}$ tablets of Tramadol, which had passed through the free zone. ${ }^{36}$ Even Syria became a significant source of supply of Tramadol, at least before the beginning of its vicious civil conflict from spring 2011 onwards.

But there were other factors at play. Chinese Tramadol in particular was far cheaper than other 'black market' supplies, especially in relation to the weight of the product. It quickly became evident that the Tramadol circulating was no longer confined to a single or dual source. Maher Kemal Mehdat, a drugs outreach worker at the Shubra Drop-in Centre, Freedom NGO estimated that a strip of 10 Tramadol pills sold for roughly $f E 200$ before the revolution was selling for fE20 a strip in October 2011, the cheaper Tramadol having been manufactured in China. ${ }^{37}$ This seemed to indicate a complete collapse in the price of the product. With respect to weight, $200 \mathrm{mg}$ of Tramadol produced in Egypt contrasted with $225 \mathrm{mg}$ of the drug to be found in some Chinese products. This conclusion was challenged in relation to the safety of Tramadol from China.

Otherwise, in Egypt there were on balance fewer of the concerns that often accompany opioids, such as HIV, Hepatitis B and different forms of infection. In Egypt the intra-venous consumption of drugs is still a relatively unusual method of intake. The preferred means of consumption is either to take the drug orally or through inhalation. The absence of a systematic programme of 'harm reduction', featuring such accoutrements as free syringes and shooting galleries, means that the mass injection of heroin and the like is not a reality in Egypt, or at least not yet. Professor Hamdi concluded that the relatively recent practice of younger, upper middle class Egyptians using needles to inject themselves with amphetamines, notably those using the brand name of either 'Max' or 'Maxtone forte', may eventually result in the spread of 'learned behaviour' among Egypt's drug consumers. ${ }^{38}$

\section{Explaining the Attraction}

The best way to explain the rapid take-off in the circulation and consumption of Tramadol is through a combination of availability, versatility and desirability. Logically enough, the fact that the availability of the drug was limited, it being only available through the prescription system, should have restricted circulation at a critical time. In reality, the thinking behind access to the drug proved to be misconceived. In Egypt, the prescription system is not as extensive as it is in many other countries, admitted Professor Hamdi. ${ }^{39}$ In 2009, the Egyptian authorities reclassified Tramadol as a Class A drug, as a warning to potential users. Previously, Tramadol had been categorised as a Class B drug, indicating that the drug regulatory authorities had initially been somewhat slow to respond to its rising threat. 
Despite the good intentions behind the re-evaluation of the danger of such a move, specialists like Professor Hamdi argue that this in fact had a perverse effect on the drug market. ${ }^{40}$ The reclassification process simply pushed the market out of the formal domain of regulatory scrutiny and onto the streets, where its transactions were effectively criminalised and hence obscured. Ironically, from a position of limited but tangible advantage through the prescription system, Egypt virtually overnight threw away its best chance of monitoring the emerging illicit 'drugs scene' in Tramadol.

The loss of any system of quality control quickly had a visible impact upon the origins of the drug, its composition and the conditions in which it was used. With Tramadol cheap to purchase and easy to consume, the market was quickly flooded. Suddenly, a new generation of poorer, Egyptian males was able to afford the drug, and hence luxuriated in its versatility. ${ }^{41}$ The fact that Tramadol quickly acquired a reputation for the enhancement of sexual performance, even though that is believed to be a transient side-effect of consumption, born more of urban legend than sustainable reality, helped to add to its aura, at least in the short term.

Appalled and mystified at the sudden and extreme swing in the price of Tramadol, some social commentators, like Maher Kemal Medhat, and others have tended to assume the existence of a hidden agenda, seeing such developments as best explained by a desire 'to anaesthetise our youth'42. The conspiracy theories were also extended to encompass macro-factors, as well as those affecting the individual. This view perceived Egypt to be under attack, 'at all gates', with respect to bringing illicit drugs into the country. With the surge in demand for Tramadol coinciding with the early phase of the revolution, there was already an enabling context in which drugs could be consumed and even celebrated at the same time. From open borders with Libya, through few internal controls, to a retreat of the public security from much of their policing functions, the constraints on the movement and consumption of drugs like Tramadol all but effectively disappeared.

The heightened impact of Tramadol, whether used on its own or as a component in drug 'cocktails', rapidly acquired a preference status, especially among males in their teens and early twenties. Tramadol could more easily be consumed as part of a poly-drug mix that suited the preferences of the consumer. In the case of Tramadol, a pain killer, the substance was often taken in conjunction with hashish, which could be used easily to generate a 'high'.

Tramadol's new users appeared to display a disdain for the possible health impact of the drug on the nervous system. They appeared readily to consume the drug, in conjunction with other substances, which gave them a sense of bravura. In such a state of psychological diversion, drugs users appeared more willing to act recklessly, and were more likely to commit acts of violence or property crime when under the influence of such substances. Of course, less quality control combined with greater poly-drug use ran the risk of creating ever more unpredictable drugs, owing to the scale of ignorance as to what was contained within the drug as much as the directly harmful effects of the drugs used in such a situation. 


\section{Some State Responses to Drug Consumption}

The initial confrontation with the Mubarak regime over drugs, and focused on Tahrir Square, was surprisingly agnostic. Many Egyptians, especially those based in the countryside adopted a 'wait and see' posture, uncertain as to what would be the likely outcome. The forces of the state were in any case somewhat depleted, especially after it became plain that the military had no intention of taking sides, at least initially. In terms of resistance, it was only the police, the intelligence and the ruling National Democratic Party (NDP) that proved to be partisan actors. Even these were far from reliable elements for the state. The backlash against the police and the burning of the NDP headquarters in central Cairo weakened pro-regime forces. Instead, the national security warning seemed to be presented in another way. A failure to fall into line would be met by a wave of criminality which, for our purposes, would include those peddling illicit drugs.

From the outset, the police were only willing to choose the battles that they could win. In Upper Egypt, the police consciously avoided confrontations with those involved in drugs-related criminality. This included avoiding clashes in cities like Asiut and Sohag, as well as much of the desert areas, where drugs such as bango, hashish and opium were openly produced. The situation was even worse in the northern Sinai Peninsula compared to Upper Egypt and the capital, where the bedouin tribes had decisively more firepower than elsewhere in the country. Their state of the art pick-ups could disappear into the interior at any time, outstripping military vehicles. According to one senior foreign diplomat, who had spent three years based in Cairo, Sinai in February 2012 was effectively out of control. ${ }^{43}$

The other main factor contributing to a sense of lawlessness in the Sinai was the provisions of the Egyptian-Israeli peace. A central stipulation of the treaty was that the Egyptian state should not be permitted to project power in the direction of Israel, to do so being considered a potential casus belli. With Israel now worrying much more about crossborder smuggling than inter-state war, this treaty requirement was quietly set aside as the impact of drugs trafficking became a bigger priority for the Jewish state in a context of evolving security threats.

Egypt did try to adopt a more uncompromising stance towards criminals, with the prison tariffs for robbery and drugs both being raised by the Presidential Council to 15 years in prison, acknowledged Dr Nasser Loza of Behman Hospital. ${ }^{44}$ However, it proved hard to derive traction for a prison-oriented deterrence strategy. In practice, this seemed to have little impact. The absence of the police on the streets encouraged criminal gangs to attack potentially high profitability outlets, of which hospital pharmacies in poor and populated areas, such as Shubra, in the capital, was but one.

It was not only in the realm of the national security state that changes on the ground had implications for policy and hence drugs-related advocacy. In 2005 Egypt had adopted its first National Strategy for Drugs, in conjunction with the UNODC. The impact was a major one, not least because it was supported by the 'First Lady', Suzanne Mubarak. The 
engagement of Mrs Mubarak helped to galvanise political will for the strategy, not least in the difficult process of coordinating the necessary inter-agency activity. The involvement of Suzanne Mubarak would also have galvanised the prime minister's office, Ahmad Nazif, being a particular ally of the Mubarak family. Amr Osman, Manager of the Fund for Drug Control and Treatment of Addiction in Cairo believes this would have ensured the necessary political will for the strategy, as long as the Mubarak political edifice remained in power. ${ }^{45}$

\section{Conclusion}

Egypt has long been a country that has consumed and even celebrated illicit drugs. At different times, various drugs have been embraced as the national drug of choice: hashish in the nineteenth century; the infamous 'white drugs' of cocaine and heroin in the 1920s and 1930s; hashish again after that; bango over the last couple of decades. Today, the synthetic opiate, Tramadol, largely appears to have taken over that role. Moreover, it has done so within a context of expanding drugs consumption, an apparent disregard for the potentially harmful effects of drugs, and with the revolutionary state poorly positioned to combat let alone reduce the existing impact of drugs on society.

The explosion in the consumption of Tramadol may be described as a perfect storm. It comprises: the collapse of a central regulatory authority in the context of the turmoil of the Egyptian revolution; the sudden affordability of such substances on the part of a stratum of young, otherwise impoverished, male Egyptians, who hitherto would have been unable to afford such substances; urban legends, covering such issues as the enhancement of sexual performance among these and other males. Important though this narrative has been it has not been the whole story. Strong evidence, notably from the Hamdi report, has established that Tramadol came to dominate the drugs scene before the toppling of the Mubarak regime.

Is it likely that Tramadol will replace the likes of bango and hashish as the dominant drug of Egyptian culture? It will certainly take a long time before Tramadol can come close to making that claim. Cultures, whether drugs-related or any other, do not shift overnight. A lot will depend on how long the acutely permissive society of drug-taking in Egypt persists. If the authoritarian national security state effectively reasserts itself under the presidency of Abdul Fatah el-Sisi, then that tide-line of drugs may also recede. If, by contrast, drugs remain a visible and central part of economic occupation as well as youthful recreation, then persuading Egyptians to disavow such practices may prove to be as difficult as it has been at any other time since the country has tried to regularise such consumption.

\section{Notes}

1. Russell, 'Egyptian Service'.

2. Youssef, 'A $1 / 4$ Gram', 429

3. Al Masry al Youm, January 2012

4. Al Masry al Youm, February 2012. 
5. Interviews with author, 2011-12.

6. Scott n.d.

7. Interview with the author.

8. Davenport-Hines, 'Pursuit of Oblivion', 227.

9. Interview with author, 13 April 2011.

10. These include such functional areas as: money laundering; international cooperation and the implementation of international agreements and conventions.

11. Krasner, 'International Regimes'.

12. McAllister, 'Drug Diplomacy', 105.

13. For a further examination of some of the themes in this paper, see Ch. 4 'Egypt: The Land of the Hashisheen' in Robins, 'Middle East Drugs Bazaar'.

14. Author participant observation, 18 November 2012.

15. Walter Armbrust, the well-known social anthropologist of Egypt and a colleague at St Antony's College, notes that the number of feature films being made during the Sadat period certainly gave the impression that drugs consumption was sharply increasing in Egypt. Conversation, 5 April 2011.

16. Confidential interview with author, 7 April 2011.

17. Al Tahrir 2013.

18. Interview with author, 20 November 2012.

19. Interview with author, 19 November 2012.

20. Interview with author, 31 October 2012.

21. Youssef, 'A $1 / 4$ Gram'.

22. Interview with author, 5 April 2011.

23. Interview with author, 9 April 2011.

24. Interview with author, 30 October 2011.

25. Interview with author, 7 February 2012.

26. Interview with author, 5 February 2012.

27. Sleem, 'Social Work Education and Impact'.

28. Interview with author, July 2011.

29. Interview with the author, April 2011.

30. Interview with author, 3 November 2011.

31. Interview with author, 11 July 2012.

32. Interview with author, 12 July 2012.

33. Nabil n.d.

34. International Herald Tribune 2015

35. Interview with author, 3 November 2011.

36. Interview with author, April 2011.

37. Interview with author, 31 October 2012.

38. Interview with author, April 2011.

39. Interview with author, April 2012.

40. Interview with author, October 2011.

41. See Crabtree, et al. 2012, 252-254 for more on poverty, demography and other contributory factors. 
42. Interview with author, February 2012.

43. Confidential interview with author, 8 February 2012.

44. Interview with author, 9 April 2011.

45. Interview with author, 11 April 2011.

\section{Bibliography}

2012. Al Maasry al Youm. 11 February. Accessed February 2012. See http://www.almasryalyoum.com/article2.aspx?ArticleID=328550\&IssuelD=2413.

2012. Al Masry al Youm. 29 January. Accessed January 2012. http://www.almasryalyoum.com/article2.aspx?ArticleID=325896\&ID=2391.

Al Tahrir. 2013. "Army returns to bombing Gazan tunnels after failing to eliminate them with water." Al Tahrir, 20 March.

Crabtree, S Ashencaren, J Parker, and A Azman. 2012. The Cup, the Gun and Civil Unrest in Muslim Societies. Lndon: Whiting \& Birch.

Davenport-Hines, Richard. 2001. The Pursuit of Oblivion: A Global History of Narcotics, 1500-2000. London: Weidenfeld \& Nicholson.

International Herald Tribune. 2015. "Arrest hints at China role in synthetic drug market." International Herald Tribune, 29 May: 10.

Krasner, Stephen D (ed). 1983. International Regimes. Ithaca: Cornell University Press.

Lavie, Smadar. 1990. The Poetics of Military Occupation. Berkeley: University of California Press.

McAllister, William B. 2000. Drug Diplomacy in the Twentieth Century. London: Routledge.

McCarthy, Rory. 2014. http://www.theguardian.com/world/. 20 April. Accessed October 27, 2014. http://www.theguardian.com/world/2010/apr/20/hamas-burns-tramadol-painkillers-sm.

Nabil, Mahmoud. n.d. http://www.civicpole.net. Accessed October 27, 2014. http://www.civicpole.net/en/on-the-ground/egyptian-view/89-tranquiliser-abuse-in-egypt.

Robins, P J. 2016. Middle East Drugs Bazaar. Production, Prevention and Consumption. London: Hurst.

Russell, Thomas. 1948. Egyptian Service, 1902-1946. London: John Murray.

Scott. 1922. "F 879/151/10." Letter from Ambassador Scott, Cairo to Lord Curzon. Cairo, 18 February.

Siegelbaum, Max, and Alessandro Accorsin. 2013. http://www.aljazeera.com. 29 November. Accessed October 27, 2014. http://www.aljazeera.com/indepth/features/2103/11/egyptwave-painkiller-addiction. 
Sleem, Houda Nassim. 2013. "The status quo of social work education and its impact on the family and children services: Lebanon." In Social Work in the Middle East, by Hassan Soliman Hussein. Abingdon: Routledge.

Viney, Stephen. 2012. http://www.egyptindependent.com. 16 May. Accessed May 16, 2012. http://www.egyptindependent.com/news/drug-addiction-rises-cairo-experts-offerrecommendations.

Young, Oran R. 1989. INternational Cooperation: Building Regimes for National Resources and the Environment. Ithaca: Cornell University Press.

Youssef, Essam. 2009. A Quarter of a Gram. Cairo: Montana Studios. 